\title{
Prospective, randomized, and comparative study of efficacy of ivermectin, benzyl benzoate $25 \%$, permethrin $5 \%$ and gamma benzene hexachloride $1 \%$ in the treatment of uncomplicated scabies
}

\author{
K. Chitra ${ }^{1}$, Swathi Ratnam R. ${ }^{2 *}$, J. Sudha ${ }^{1}$, G. Suryanarayana ${ }^{3}$
}

\author{
${ }^{1}$ Department of Pharmacology, ${ }^{3}$ Department of Dermatology, Andhra Medical College, Visakhapatnam, AP, India \\ ${ }^{2}$ Department of Pharmacology, Government Medical College, Balaga, Srikakulam, AP, India
}

Received: 08 January 2020

Revised: 05 April 2020

Accepted: 07 April 2020

\section{*Correspondence:}

Dr. Swathi Ratnam R.,

Email: sweetyswathi12@gmail.com

Copyright: (C) the author(s), publisher and licensee Medip Academy. This is an open-access article distributed under the terms of the Creative Commons Attribution Non-Commercial License, which permits unrestricted non-commercial use, distribution, and reproduction in any medium, provided the original work is properly cited.

\begin{abstract}
Background: Scabies is an infectious and contagious human skin disease. The aim of the study was to study the efficacy and safety of four different treatment modalities in clinically diagnosed cases of scabies of single dose of oral ivermectin and commonly used topical scabicidal agent's benzyl benzoate $25 \%(\mathrm{BB})$, permethrin $5 \%$ and gamma benzene hexachloride $1 \%$ (GBHC).

Methods: This study was carried out in the Department of Dermatology, Andhra Medical College, Visakhapatnam. 200 patients diagnosed of scabies were included in the study during the period from August 2013 to July 2014. The percentage of improvement was compared between four groups. Intergroup comparison between two groups was done Chi square test.

Results: In the present study a greater number of patients were students (54.5\%). Subsidence of lesion and itching with oral ivermectin given as a single dose $(200 \mu \mathrm{g} / \mathrm{kg}$ body weight) was $45(90 \%)$ and $44(88 \%)$, with topical permethrin 5\% lotion single application 48 (96\%), $47(94 \%)$, with topical GBHC $1 \%$ lotion $40(80 \%)$ patients, 38 (76\%). Topical application of BB lotion $25 \%$ was $38(76 \%)$, and $36(72 \%)$ at fourth week.

Conclusions: In the present study permethrin $5 \%$ cream was found to be more effective among topical agents. Both $\mathrm{BB}$ and $\mathrm{GBHC} 1 \%$ lotion are being inexpensive and they can be used as an alternative treatment in developing country like India.
\end{abstract}

Keywords: Scabies, Ivermectin, Benzyl benzoate, Permethrin and gamma benzene hexa chloride

\section{INTRODUCTION}

Scabies is an infectious and contagious human skin disease caused by the mite Sarcoptes scabiei var. hominis. It is characterized by papular or vesicular eruption with intense itching especially at night. Scabies is transmitted readily, often throughout an entire household, by prolonged skin-to-skin contact with an infected person. Scabies affects people of all countries, particularly children ofhex the developing nations. The highest incidence is in countries with hot, tropical climates, where infestation is endemic especially in communities where overcrowding and poverty coexists. ${ }^{1}$ Rate of scabies occurrence vary from $0.3 \%$ to $46 \%$ as per the recent literature. ${ }^{2}$ In 2010 it was estimated that the direct effects of scabies infestation on the skin alone let to more than 1.5 million YLDS (years lived with disability), and the indirect effects of complications on renal and cardiovascular functions are far greater. ${ }^{1}$ Scabies infestation is frequently complicated by bacterial skin 
infections such as impetigo, cellulitis and abscess due to Streptococcus pyogenes and Staphylococcus aureus. Such bacterial skin infections predispose to serious suppurative and non suppurative sequelae. There are about three hundred million cases of scabies in the world each year. With the launch of International Alliance for the Control of Scabies (IACS) in 2012, which is recently formed group from across the globe to advance the agenda of scabies control, shows the current epidemiological situation for scabies across the world. Scabies recently included in the WHO NTD (neglected tropical disease) list is an important step towards greater recognition of this pathogen as a cause of considerable global morbidity and mortality. ${ }^{3}$

A meta-analysis reported that, there is no conclusive evidence that oral Ivermectin is superior to topical preparations for treating common scabies in the community setting. ${ }^{4}$ Therefore this type of research study is done with an aim to determine an easy, safe, effective and better patient compliance drug which can be an ideal anti-scabietic drug in future.

\section{METHODS}

This study was a prospective, randomized, and comparative clinical trial carried out in the Department of Dermatology in patients of uncomplicated scabies, King George Hospital, attached to Andhra Medical College, Visakhapatnam during August 2013 to July 2014. 200 patients diagnosed of scabies were allocated for each of four groups by following simple random sampling procedure using lottery method. Ethical clearance was obtained from Institutional ethics committee of Andhra Medical College, Visakhapatnam. Detailed informed consent form was signed by all adult patients or by parents of the children enrolled in the trial after a detailed explanation and clarification of doubts regarding the study. Basing on the inclusion criteria, newly diagnosed patients of scabies of either gender belonging to the age group between 5 to 60 years who are willing to participate for either topical therapy or oral therapy, complaint of nocturnal itching and presence of typical scabietic lesions like papule, vesicle, nodulesuncomplicated scabies.

Patients were excluded who are less than 5 years and elderly patients more than 60 years, pregnant women, lactating women, women of child bearing age planning for conception in near future, who were not willing for follow up, taking any concurrent medication for other illness, with any other associated skin diseases which may alter the picture of scabies, Any serious systemic illness particularly CNS disorders, known/suspected immunocompromised individual, who have taken any anti-scabietic treatment in the previous week. Routine blood tests were done. Severity of lesions and site of lesions and grading of itching recorded for each patient.

\section{Interventions}

Group A patients received tablet ivermectin (oral)- 200 $\mu \mathrm{g} / \mathrm{kg}$ to be consumed as single dose on empty stomach. Available as $6 \mathrm{mg} / 12 \mathrm{mg}$. Group B patients received permethrin $5 \%$ cream to be applied once to the whole body below neck and left overnight for 8 hours. Group C patients was treated with benzyl benzoate $25 \%$ lotion to be applied to the whole body below neck and left for 24 hours. Group D patients was advised GBHC- 1\% lotion to be applied to the whole body below neck and left overnight for 8 hours.

Participants on intervention B, C, D group were advised to bath with warm water before application of medication and scrub bath was taken 12 hours later. The participants were recalled after one week and again at fourth week for follow up evaluation. During the follow up patients were observed for cure rate and adverse drug reaction (ADR) monitoring. The demographic data of the participants were collected in the case record form (CRF) by the principle investigator. At each follow up the participants were examined by two doctors, the dermatologist and the principle investigator. Patients were advised not to use or mix with any other treatment including antipruritic or antihistaminic medicines. All participants were issued Benzyl benzoate lotion $25 \%$ for topical application for their family members and close contacts, as per the standard treatment guidelines to check the re-infestation of the participants. Participants were reinforced with the importance of treatment of family members and other close contacts during each visit.

At the initial visit the baseline itching and clinical grading score was done. All the details were recorded and the efficacy was assessed on the basis of two parameters.

\section{Clinical grading score}

The primary efficacy parameter was total number of lesions. Severity of lesions was clinically graded on a scale of 0 to 3 arranged as follows, $0=$ free of lesion (no lesion), $1 \leq 10$ lesions (mild), 2=11-49 lesions (moderate) and $3 \geq 50$ lesions (severe). ${ }^{5}$

\section{Itching grading score}

The secondary efficacy parameter was assessment of reduction in severity of pruritus, considering the pruritus at first visit as $100 \%$. The patient was asked for reduction in intensity of pruritus on subsequent visits and on basis of that grading was done on the given scale by the observer. $^{5}$

\section{Pruritus grading scale}

Pruritus is graded as follows, $0=0 \%$ (no pruritus); $1=(1-$ $25 \%$ ) (mild pruritus); $2=(26-50 \%)$ (moderate pruritus), $3=(51-75 \%)$ (severe pruritus); and $4=(76-100 \%)$ (very severe pruritus). ${ }^{5}$ 


\section{Stastistical analysis}

The percentage of improvement was compared between four groups. Intergroup comparison between two groups was done Chi square test. For all statistical tests, $\mathrm{p}$ value $<0.05$ were considered to be statistically significant.

\section{RESULTS}

Patients who were included in study were divided into 4 groups of 50 patients each. In the present study most of the patients belonged to the age group of 11-20 years 75 $(37.5 \%)$. The number of patients in age group of 21-30 years and 6-10 years were $53(26.5 \%)$ and $31(15.5 \%)$ respectively. Male constituted to the majority of patients. Male: female ratio is approximately 3:2.

Out of 200 patients, majority were students who constituted to $119(54.5 \%)$ followed by housewives 37 (18.5\%), coolie $14(7 \%)$, agriculturists $13(6.5 \%)$ and others $12(6 \%)$, hotel workers $9(4.5 \%)$, teachers $6(3 \%)$.

Family history of scabies was positive in $169(84.5 \%)$ patients. Scabies gets transmitted to close contacts at home. Therefore, close contacts are to be treated to be prevent re-infestation. In the present study nocturnal itching was present in all 200 patients i.e., 100\% of patients.

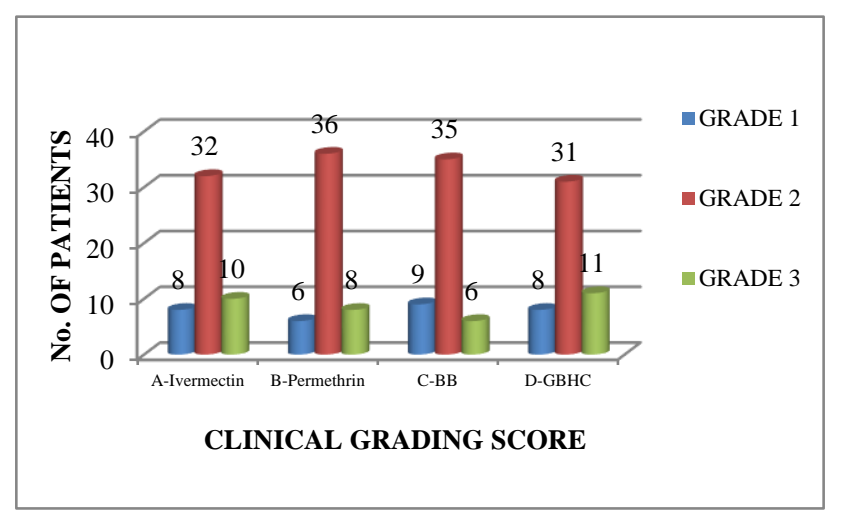

Figure 1: Represents clinical grading score.

Number of patients with respect to the clinical grade (lesions) in each treatment groups with respect to lesions on the first day. Ivermectin group- number of patients in grade 1 was $8(16 \%)$ in grade 2 was $32(64 \%)$ and in grade 3 was $10(20 \%)$. Permethrin (B)- number of patients in grade 1 was $6(12 \%)$ in grade 2 was $36(72 \%)$ and in grade 3 was $8(16 \%)$. BB (C)- number of patients in grade 1 was $9(18 \%)$ in grade 2 was $35(70 \%)$ and in grade 3 was $6(12 \%)$. GBHC (D)- number of patients in grade 1 was $8(16 \%)$ in grade 2 was $31(62 \%)$ and in grade 3 was $11(22 \%)$.

Ivermectin (A)- during first follow up patients in higher grades improved to lower grades and patients in grade 1, $8(16 \%)$ got cured and $27(54 \%)$ in grade 2 got cured.
Totally 35\% got cured for lesions in this group. Permethrin (B)- patients in grade 1, 6 (12\%) got cured and $33(66 \%)$ got cured in grade 2 . Totally $39(78 \%)$ got cured during first follow up. $\mathrm{BB}(\mathrm{C})$ - patients in grade 1,9 (18\%) got cured and $19(38 \%)$ got cured in grade 2. Totally $28(56 \%)$ got cured during first follow up in this group. GBHC (D)- patients in grade 1, $8(16 \%)$ got cured and $22(44 \%)$ got cured in grade 2 . Totally $30(60 \%)$ patients got cured during the first follow up. In all treatment groups there were no patients in grade 3 .

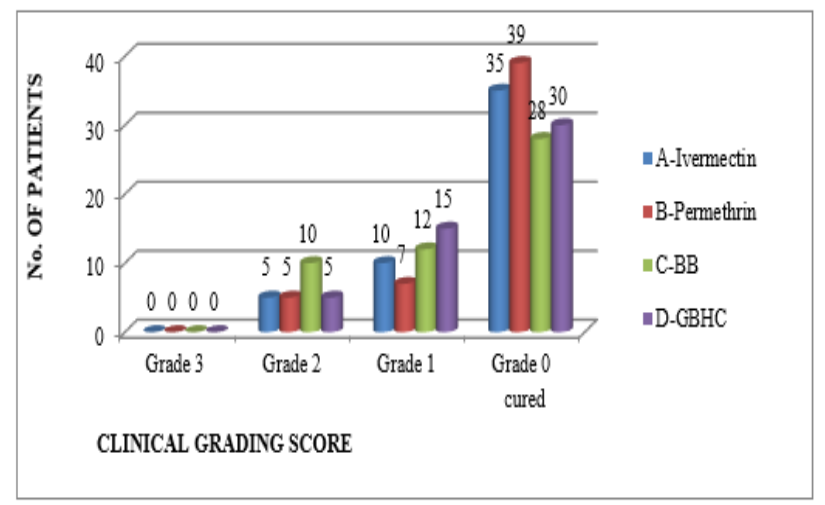

Figure 2: First follow up after first week lesion.

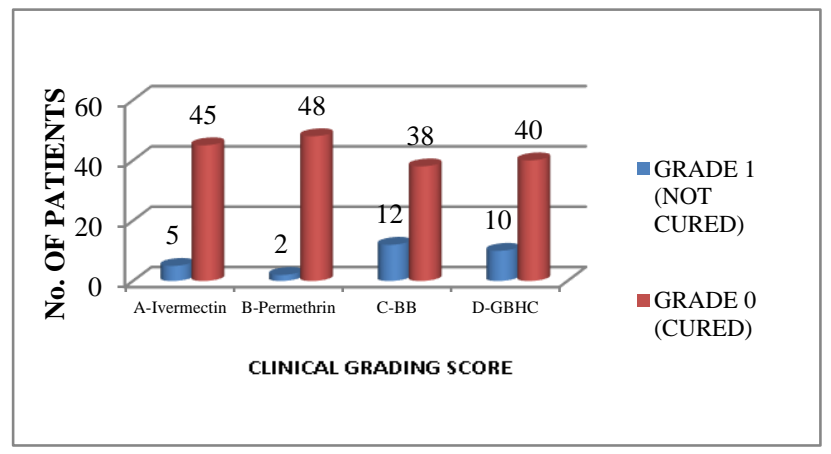

Figure 3: Second follow up in fourth week lesion.

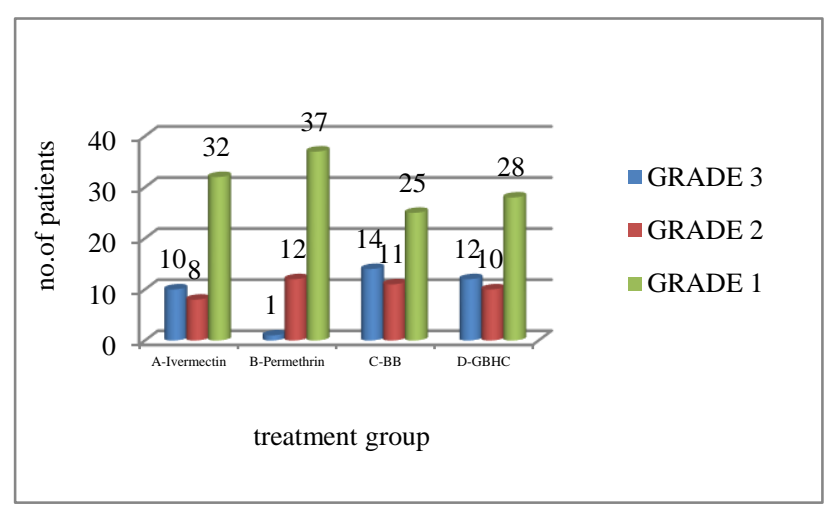

Figure 4: First follow up after first week itching.

Ivermectin (A)- during second follow up patients in higher grades improved to lower grades and out of patients in grade 1, $10(20 \%)$ got cured. Totally $45(90 \%)$ got cured for lesions in this group. Number of patients 
not cured is $5(10 \%)$. Permethrin (B)- out of patients in grade $1,7(12 \%)$ got cured and $2(4 \%)$ got cured in grade 2. Totally $48(96 \%)$ got cured during second follow up. Number of patients not cured is $2(4 \%)$. BB (C)- out of patients in grade 1, $10(20 \%)$ got cured. Totally $38(76 \%)$ got cured during second follow up in this group. Number of patients not cured is $12(24 \%)$. GBHC (D)- out of patients in grade 1-10 (20\%) got cured. Totally $40(80 \%)$ patients got cured during the second follow up. Number of patients not cured is $10(20 \%)$. Baseline itching severity was considered very severe- $(100 \%)$ in all 200 patients.

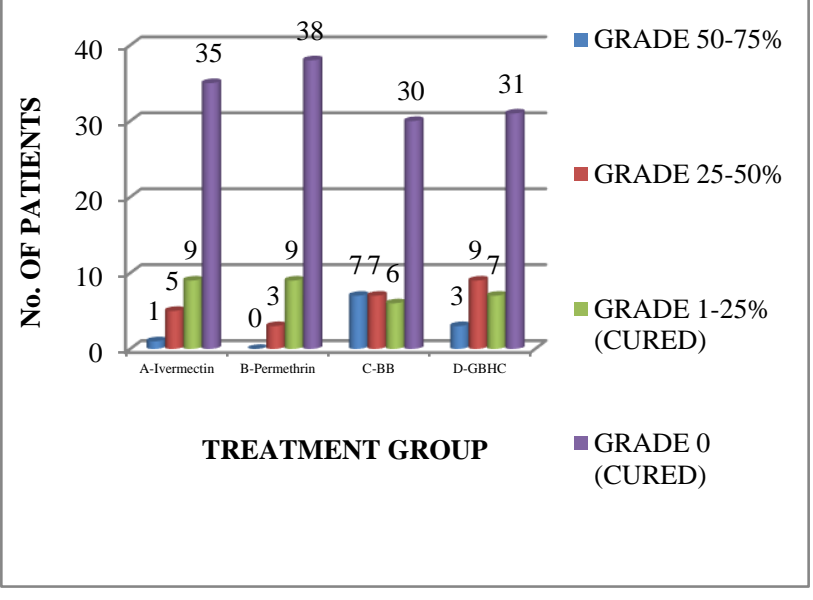

Figure 5: Second follow up in fourth week itching.

During first follow up at the end of first week, patients in all groups improved from grade 3 to grade 1 . Ivermectin(A) out of 50 patients, $10(20 \%)$ grade came down to (50$75 \%$ ) (grade 3$), 8(16 \%)$ came down to $(25-50 \%)$ grade 2 , and rest of the patients $32(64 \%)$ got (1-25\%) grade 1 for itching. Permethrin- B out of 50 patients, $1(2 \%)$ grade came down to $(50-75 \%)$ grade $3,12(24 \%)$ came down to $(25-50 \%)$ grade 2 , and rest of the patients $37(74 \%)$ got (1-25\%) grade 1 for itching. BB- (C) out of 50 patients, $14(28 \%)$ grade came down to $(50-75 \%)$ grade 3,11 (22\%), came down to $(25-50 \%)$ grade 2 , and rest of the patients $25(50 \%)$ got $(1-25 \%)$ grade 1 for itching.
GBHC- (D) out of 50 patients, $12(24 \%)$ grade came down to (50-75\%) grade 3, $10(20 \%)$, came down to (25$50 \%$ ) grade 2 and rest of the patients $28(56 \%)$ got (1$25 \%$ ) grade 1 for itching.

Ivermectin - (A) at first follow up 18 (36\%) patients were not cured, out of them, 9 (18\%) improved to grade $1-25 \%$ and $3(6 \%)$ came down to grade 0 at $4^{\text {th }}$ week. Both these grades were considered as cured. Total no of patients cured for itching is $44(88 \%)$ Number of patients not cured is $6(12 \%)$.

Permethrin- B at first follow up 13 (26\%) patients were not cured, out of them, 9 (18\%) improved to grade (1$25 \%)$ and $1(2 \%)$ came down to grade 0 at $4^{\text {th }}$ week. Both these grades are considered as cured. Total no of patients cured for itching is $47(94 \%)$, number of patients not cured is $3(6 \%)$.

BB- (C) at first follow up $25(50 \%)$ patients were not cured, out of them, 6 (12\%) improved to grade (1-25\%) and $5(10 \%)$ came down to grade 0 at $4^{\text {th }}$ week. Both these grades were considered as cured. Total no of patients cured for itching is $36(72 \%)$. Number of patients not cured is $14(6 \%)$.

GBHC- (D) at first follow up $22(50 \%)$ patients were not cured, out of them, 7 (14\%) improved to grade (1-25\%) and $6(12 \%)$ came down to grade 0 at fourth week. Both these grades were considered as cured. Total number of patients cured for itching is $38(76 \%)$. Number of patients not cured is $12(24 \%)$.

In various regimens at the end of 4 weeks as depicted in the above Table 1; there was statistical significance with results obtained with topical permethrin $5 \%$ with $\mathrm{BB}$ lotion $25 \%$ with regards to parameter for both itching and severity of lesion. Similarly, there was statistical significance with results obtained by permethrin 5\% cream with GBHC $1 \%$ lotion in consideration with both the parameters itching and severity of lesions. Oral Ivermectin shows statistical significance with BB lotion with parameter itching is considered. Oral ivermectin and permethrin results were not statistically significant for both parameters.

Table 1: Comparison of results of various regimens at fourth week.

\begin{tabular}{|c|c|c|c|c|c|}
\hline \multirow[b]{2}{*}{ Regimens } & \multirow[b]{2}{*}{ No. cases } & \multicolumn{2}{|c|}{ Lesion at fourth week } & \multicolumn{2}{|c|}{ Itching at fourth week } \\
\hline & & $\begin{array}{l}\text { Cured } \\
\mathbf{N}(\%)\end{array}$ & $\begin{array}{l}\text { Not cured } \\
\mathbf{N}(\%)\end{array}$ & $\begin{array}{l}\text { Cured } \\
\mathbf{N}(\%)\end{array}$ & $\begin{array}{l}\text { Not cured } \\
\text { N }(\%)\end{array}$ \\
\hline A-IV & 50 & $45(90)$ & $5(10)$ & $44(88)$ & $6(12)$ \\
\hline B-PM & 50 & $48(96)$ & $2(4)$ & $47(94)$ & $3(6)$ \\
\hline C-BB & 50 & $38(76)$ & $12(24)$ & $36(72)$ & $14(28)$ \\
\hline D-GBHC & 50 & $40(80)$ & $10(20)$ & $38(76)$ & $12(24)$ \\
\hline
\end{tabular}



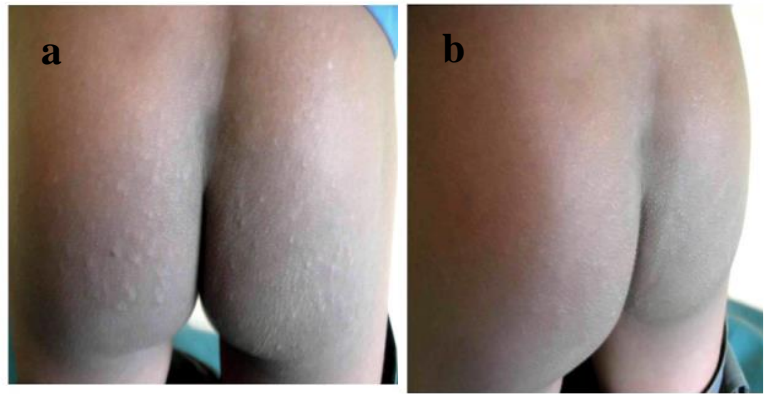

Figure 6: Response to oral ivermectin group (a) before treatment and (b) after treatment 4th week.
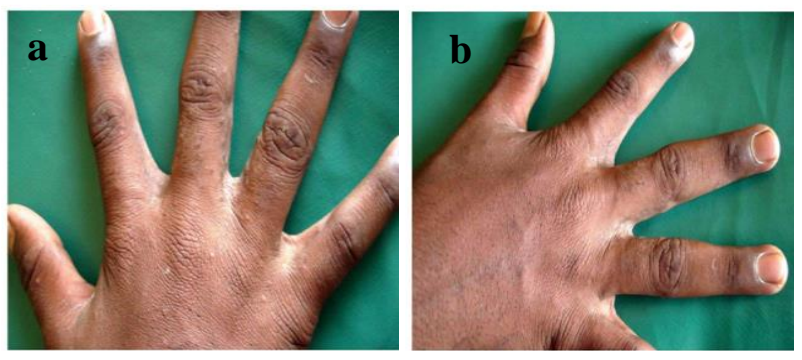

Figure 7: Response to permethrin 5\% lotion (a) Before treatment and (b) after treatment 4th week.
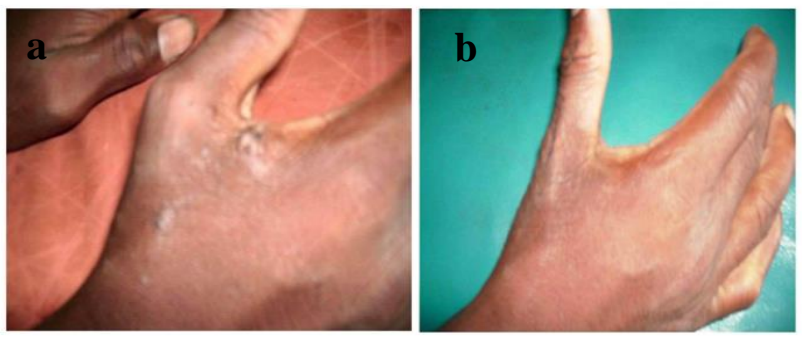

Figure 8: Response to benzyl benzoate $25 \%$ lotion (a) before treatment and (b) after treatment 4th week.
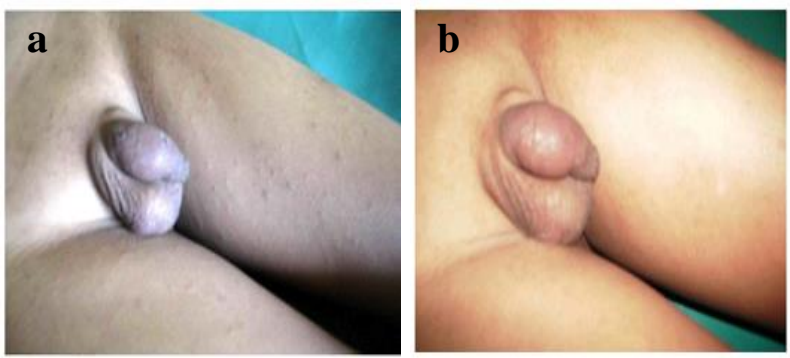

Figure 9: Response to GBHC 1\% (a) before treatment and (b) after treatment 4th week.

\section{DISCUSSION}

In our study, majority of the patients $(37.5 \%)$ belonged to the age group of 11-20 years followed by 21-30 years who constituted to $26.5 \%$ of scabies. Children between 610 years constituted to $15.5 \%$ and very few people belonged to 41 years and above. Thus, scabies was found to be more common in children and young adults. Similar results were also found in others studies like Gulati et al. ${ }^{6}$ The higher incidence of scabies found in students is due to multiple causes like playing together in the school, living together in hostels and the habit of using the dresses and linen of the friends, which add to the transmission of the disease in them. In the present study males constituted $58 \%$ whereas female constituted $42 \%$ and thus the male to female ratio was approximately $3: 2$. The higher prevalence among the middle socio-economic group $(71.5 \%)$ followed by the low-income group $(22.5 \%)$. Bedi, Nair, Hati et al, Gulati et al, have observed higher prevalence of scabies in low and middle socio-economic groups. ${ }^{6-9}$

In the present study, nocturnal itching was present in all of the patients. Nair et al, found nocturnal itching in $100 \%$ of the patients. ${ }^{8}$ Thus, it may be a helpful information in making the diagnosis, especially in the absence of facilities for demonstrating the mite.

\section{Response to treatment in various regimens}

With oral ivermectin given as a single dose $(200 \mu \mathrm{g} / \mathrm{kg}$ body weight), out of 50 patients considering the lesions as the parameter 35 (70) patients improved at the end of 1 week and 15 (20) at fourth week. Total number of patients showing after complete subsidence at fourth week was $50(90 \%)$. Similarly considering severity of itching as the parameter in 50 patients, improvement was seen in $35(70 \%)$ and $9(18 \%)$ at fourth week. Total number of patients who showed improvement was 44 (88\%). Usha et al and Chouela et al, found that a single dose of Ivermectin provided a cure rate of $70 \%$, which increased to $95 \%$ with 2 doses at a 2 weeks interval. ${ }^{10,11}$

With topical permethrin 5\% lotion single application: out of 50 patients, cure of lesion was seen in $39(78 \%)$ at the end of $1^{\text {st }}$ week and $9(18 \%)$ at fourth week respectively. Total number of patients cured at fourth week was 48 (96\%). Considerably the severity of itching number of patients cured was $37(74 \%)$ and $10(20 \%)$ at the end of $1^{\text {st }}$ week and fourth week respectively. Total number patients cured at fourth week were 47 (94\%). Zargari et al, showed $84.6 \%$ improvement after 2 weeks of therapy. ${ }^{12}$ In this study we observed that Permethrin decrease pruritus to $74 \%$ compared to $88 \%$ in ivermectin. This is comparable to Bachewar et al study. ${ }^{13}$

In present study permethrin scored over Ivermectin in providing statistically significant higher cure rates at 4 weeks post-treatment. This may have an important bearing in highly contagious disease like scabies where chain or risk of transmission of disease may curbed at a relatively early stage.

With topical GBHC $1 \%$ lotion: out of 50 patients in the present study with lesion as the parameter, improvement was seen in $30(60 \%)$ and $10(20 \%)$ of the patients at the 
end of $1^{\text {st }}$ week and between $1^{\text {st }}$ to $4^{\text {th }}$ weeks. Total improvement was seen in $40(80 \%)$ patients.

Considering the severity of itching as the parameters, improvement was seen in $28(56 \%)$ and $10(20 \%)$ of patients at the end of $1^{\text {st }}$ week and between $1^{\text {st }}$ and 4 th week. The total patients improved were seen in 38 (76\%). Taplin et al, have found cure rate $65 \%$, Zargari et al $48.9 \% .^{12,14}$

\section{With topical application of BB lotion $25 \%$}

In the present study out of 50 patients, considering the severity of lesion patients improved at the end of $1^{\text {st }}$ week and between $1^{\text {st }}$ to the $4^{\text {th }}$ weeks was $28(56 \%)$ and 10 $(20 \%)$ respectively. At end $4^{\text {th }}$ weeks total patients improved was $38(76 \%)$.

Considering the severity of itching as the parameter, patients' improvement was seen in $25(50 \%)$ and 11 $(22 \%)$ at the end of $1^{\text {st }}$ week and $1^{\text {st }}-4^{\text {th }}$ weeks respectively. Total number of patients improved at $4^{\text {th }}$ weeks was $36(72 \%)$. Glaziou et al conducted investigator-blind trial with oral Ivermectin versus topical BB lotion. After 30 days of treatment follow up showed a cumulative recovery cure rate of $70 \%$ and $48 \%$ with BB lotion. ${ }^{15}$

\section{CONCLUSION}

In the present study permethrin $5 \%$ cream was found to be more effective among topical agents. In present study permethrin scored over Ivermectin in providing statistically significant higher cure rates at 4 weeks post treatment. This may have an important bearing in highly contagious disease like scabies where chain or risk of transmission of disease may curbed at a relatively early stage. Though the results obtained with oral ivermectin were slightly low compared to permethrin, the patient compliance was very good. Permethrin was significantly more effective than benzyl benzoate and GBHC $1 \%$. Both benzyl benzoate and GBHC $1 \%$ lotion are being inexpensive and they can be used as an alternative treatment in developing country like India.

\section{ACKNOWLEDGEMENTS}

The authors are thankful to all the patients who gave their full support to carry out this research work easily.

Funding: No funding sources

Conflict of interest: None declared

Ethical approval: The study was approved by the Institutional Ethics Committee

\section{REFERENCES}

1. Bulletin World Health Organisation (2012) Neglected tropical diseases: diseases covered by NTD department. Available: http://www.who.int,neglected diseases/diseases/en. Accessed on 05 April 2019.

2. Towards the Global control of Human scabies. PLOS Neglected Tropical Diseases; August 2013/volume 7/issue 8/e2167 www.plosntds.org. Accessed on 05 April 2019.

3. Andrew Steer IACS Blog Post on globalhealth.thelancet.com Jul 2014.

4. Epidemiology and management of common skin diseases in children in developing countries. Geneva: World Health Organisation; 2005.

5. Davis JS, Gloughlin MS, Tong SY, Walton SF, Currie BJ. A novel clinical grading scale to guide the management of crusted scabies. PLoS Negl Trop Dis. 2013;7(9):2387.

6. Gulati PV, Sachder TR, Varma RK. Scabies - An epidemiological study in a resettlement colony. Indian J Dermatol Verenereol Leprol. 1981;47(6):299-302.

7. Bedi TR. Human scabies - A continuing problem. Indian J Dermatol Verenereol Leprol. 1976;42:235-6.

8. Nair BK, Joseph A, Kandamutham M. Epidemic scabies. Indian J Med Res. 1977;65(4):513-8.

9. Hati AK, Chaudhary DSR, Gupta R. Clinico parasitological studies on scabies. J Dermatol Vereneol. 1974;40:3-4.

10. Usha V, Nair TV. A comparative study of oral Ivermectin and topical permethrin cream in the treatment of scabies. J Am Acad Dermatol. 2000;42:236-40.

11. Chouela EN, Abeldano AM, Pellerano G, Laforgian, Paple RM, Garsd A. Equivalent therapeutic efficacy and safety of Ivermectin and Lindane in the treatment of human scabies. Arch Dermatol. 1999;135:651-5.

12. Zargari O, Golchai J, Sobhani A, Dehpour AR, Ashkevari SS, Alizadeh N, et al. Comparison of the efficacy of topical $1 \%$ Lindane versus $5 \%$ permethrin in scabies: A randomized, double blind study. Indian J Dermatol Venereol Leprol. 2006;72:33-6.

13. Bachewar NP, Thawani VR, Mali SN, Gharpure KJ, Shingade VP. Comparison of safety, efficacy, and cost effectiveness of Benzyl Benzoate, Permethrin, and Ivermectin in patients of scabies. Indian $\mathbf{J}$ Pharmacol. 2009;41(1):9-14.

14. Taplin D, Meinking TL, Porcelain SL, Castillero PM, Chen JA. Permethrin 5\% dermalcream: A new treatment for scabies. J Am Acad Dermatol. 1986;15:991-1001.

15. Glaziou P, Cartel JL, Alzieu P, Briot C, Pelat MJP, Martin PM. A Randomised investigator - blinded trial of oral ivermectin versus BB $10 \%$. Trop med Parasitol. 1993;44(4):331-2.

Cite this article as: Chitra K, Ratnam SR, Sudha J, Suryanarayana G. Prospective, randomized, and comparative study of efficacy of ivermectin, benzyl benzoate $25 \%$, permethrin $5 \%$ and gamma benzene hexachloride $1 \%$ in the treatment of uncomplicated scabies. Int J Basic Clin Pharmacol 2020;9:712-7. 